\title{
Correlation between the Korean pork grade system and the amount of pork primal cut estimated with AutoFom III
}

\author{
Yunhwan Park ${ }^{1 \#}$, Eunyoung Ko"\# ${ }^{2 \#}$ Kwangwook Park², Changhyun Woo², \\ Jaeyoung Kim¹, Sanghun Lee ${ }^{1}$, Sanghun Park1, Yun-a Kim¹, Gyutae Park ${ }^{1}$ \\ and Jungseok Choi ${ }^{1 *}$ \\ ${ }^{1}$ Department of Animal Science, Chungbuk National University, Cheongju 28644, Korea \\ ${ }^{2}$ Dodram Pig Farmers Cooperative, Incheon 17405, Korea
}

\section{Abstract}

It is impossible to know the amount of pork primal cut by pig carcass grade which is determined only by carcass weight and backfat thickness in the Korean Pig Carcass System. The aim of this study was to investigate the correlation between the pig carcass grade and the amount of pork primal cut estimated with AutoFom III. A total of 419,321 Landrace, Yorkshire, and Duroc (LYD) pigs were graded with the Korean Pig Carcass Grade System. Amounts of belly, neck, loin, tenderloin, spare ribs, shoulder, and ham were estimated with AutoFom III. Regression equations for seven primal cuts according to each grade were derived. There were significant differences among the three carcass grades due to heteroscedasticity variance $(p<0.0001)$. Three regression equations were derived from AutoFom III estimation of primal cuts according to carcass grades. The coefficient of determination of the regression equation was 0.941 for grade $1^{+}, 0.982$ for grade 1 , and 0.993 for grade 2 . Regression equations obtained from this study are suitable for AutoFom III software, a useful tool for the analysis of each pig carcass grade in the Korean Pig Carcass Grade System. The high reliability of predicting the amount of primal cut with AutoFom III is advantageous for the management of slaughterhouses to optimize their product sorting in Korea.

Keywords: Pig carcass grade, AutoFom III, Regression, Primal cuts, Heteroscedasticity

\section{INTRODUCTION}

With increasing national income in Korea, the consumption of meat per capita has increased. Because of that, quality control of meat produced is necessary. The Animal Products Grading Service in Korea has been established in 1989. The grading system has led to many changes in the production, distribution, and consumption of livestock products [1]. The Korean pig carcass system is divided into grade $1^{+}$, grade 1 and grade 2 according to carcass weight and back fat thickness (Table 1 ). Meat quality is judged by subjective marbling level, meat color, fat color, degree of maturity, and texture of whole pig carcass. It has contributed to the development of the livestock industry which has changed from live 
Yun-a Kim

https://orcid.org/0000-0002-5505-030X

Gyutae Park

https://orcid.org/0000-0003-1614-1097

Jungseok Choi

https://orcid.org/0000-0001-8033-0410

Competing interests

No potential conflict of interest relevant to

this article was reported.

Funding sources

Not applicable.

\section{Acknowledgements}

This work was supported by the Dodram Quality Control Management Team of Dodram Pig Farmers Cooperative. This work was supported by a grant (715003-07) from the Research Center for Production Management and Technical Development for High Quality Livestock Products through Agriculture, Food and Rural Affairs Convergence Technologies Program for Educating Creative Global Leader, Ministry of Agriculture, Food and Rural Affairs. This work also was supported by the National Research Foundation of Korea (NRF) grant funded by the Ministry of Education (No. 2020R1A4A1017552, 2020R1G1A1006498).

Availability of data and material Upon reasonable request, the datasets of this study can be available from the corresponding author.

Authors' contributions

Conceptualization: Park Y, Ko E, Kim J, Choi J. Data curation: Park Y, Ko E, Kim J.

Formal analysis: Park Y, Ko E, Kim J.

Methodology: Park Y, Kim J.

Software: Park Y, Kim J.

Validation: Park K, Woo C, Lee S.

Investigation: Park S, Kim YA, Park G.

Writing - original draft: Park Y, Ko E, Kim J.

Writing - review \& editing: Park Y, Kim J, Choi J.

Ethics approval and consent to participate This article does not require IRB/IACUC approval because there are no human and animal participants.
Table 1. Korean pig carcass grade system

\begin{tabular}{lcc}
\hline Primary carcass grade & Carcass weight $\mathbf{( k g )}$ & Backfat thickness $(\mathbf{m m})$ \\
\hline $1^{+}$ & $83-92$ & $17-24$ \\
1 & $80-82$ & $15-27$ \\
& $83-92$ & $15-16$ \\
& $83-92$ & $25-27$ \\
& $93-97$ & $15-27$ \\
2 & & Neither $1^{+}$nor 1 \\
\hline
\end{tabular}

Korean Ministry of Agriculture, Food and Rural Affairs Notification 2014-4 [2].

animals to meat products, causing conversion from warm carcass to cold carcass distribution. It has also prevented meat quality degradation, increased the reliability of distribution, and provided reasonable price formation. Data from the grading system are also helpful for the development of breeding and rearing technology. In Korea, there is a large difference in market price for each pork cut [3]. Thus, it is important to evaluate the amount of each part. However, the Korean grading system of pork does not know the weight of each pork primal cut until primal cuts are separated because the grade of pork is only evaluated based on carcass quality such as carcass weight and backfat thickness.

There are several no-destructive techniques for analyzing pig carcasses worldwide, including dual-energy x-ray absorptiometry [4], magnetic resonance imaging [5], computed tomography [6], infrared reflectance spectroscopy [7], and ultrasound imaging [8]. Dual-energy x-ray absorptiometry, magnetic resonance imaging, and computed tomography are more accurate than ultrasound imaging [9]. However, ultrasound imaging has advantages of being applicable to any carcass size with a reasonable price, no radiation, and real time measurement $[8,9]$. These techniques are important for performance testing, grading, and final selection or payment of meat-producing animals.

On-line grading of pig carcasses by ultrasound technology is widely used in European livestock industry. It is a non-invasive and fully automated technology that enables a rapid feedback to slaughter houses on lean meat percentage, primal yields, and specific traits of individual carcasses. Frontmatec Smoerum A/S (formerly known as Carometec A/S, Smoerum, Denmark) launched an ultrasound-based classification system called AutoFom III in 2009. It is used for grading pig carcass in more than 14 countries. Janiszewski et al. [10] have reported that AutoFom III shows very high accuracy for analyzing loin, ham, and belly contents of pig carcass, with coefficients for determining belly-muscle thickness and the percentage of meat in ham of 0.98 and 0.93 in regression equations, respectively. When weights of pork primal cuts were compared to predicted values by AutoFom III, cross-validated prediction accuracies of calibration models were high (0.77-0.86) [11].

The price of pork in pig farms is determined by the pork carcass grade based on carcass weight and backfat thickness. However, pork is sold by primal cuts. Prices of pork primal cuts are different in the market. It is impossible to accurately estimate the amount of pork primal cut with the current Korean Pig Carcass Grade System. To determine an appropriate pork price, the amount of pork primal cuts needs to be predicted according to each grade. Therefore, the objective of this study was to investigate the correlation between pig carcass grade and the amount of pork primal cut estimated by AutoFom III to provide a means to predict the amount of pig primal cut according to each grade. 


\section{MATERIALS AND METHODS}

\section{Animals}

Pigs used in this estimation test were Landrace $x$ Yorkshire, F1 $x$ Duroc (LYD) crossbreds and were bred with the artificial insemination and the feed provided by Dodram pig farmers cooperative. All pigs from farms having contracts with Dodram were transported to the Dodram LPC in Anseong, Gyeonggi Province, Korea from January 2018 to December 2018. Pigs were slaughtered according to the Livestock Hygiene Control Act. A total of 419,321 heads except for non-grade carcasses in the Korean Pig Carcass Grade System were used in this experiment.

\section{AutoFom III analysis}

After hair removal of pig carcasses, an AutoFom III (Frontmatec Smoerum A/S, Smørum, Denmark) equipment was used prior to evisceration of carcasses. AutoFom III equipment has 16 ultrasound transducers. These transducers are excited in turn with repeated frequency of approximately $5 \mathrm{kHz}$. Scanning of the carcass generates 48 ultrasound images with information on skin, fat, and lean measures. How to use AutoFom III was described in detail in our previous study [11]. Using AutoFom III, amounts of seven pork parts (belly, neck bone-out, tenderloin, spare ribs, shoulder bone-out, and ham bone-out) were estimated.

\section{Grading of pig carcass}

Pig carcasses were graded with the Korean Pig Carcass Grade System (Table 1). The pig carcass weight was measured with an electronic scale and expressed as an integer in $\mathrm{kg}$ unit. The left half carcass was used to measure the backfat thickness. The backfat thickness between the last thoracic vertebra and the first lumbar vertebra and that between the 11th and 12th thoracic vertebrae were measured with a ruler. The average of the two values was then calculated and used for analysis. A total of 419,321 heads were graded in this experiment.

\section{Statistical analysis}

The significance of testing of each grade was investigated by a $t$-test of heteroscedasticity variance. Excess kurtosis and skewness were calculated to investigate distribution characteristics of seven carcass parts. Regression equation was obtained with the weight of the carcass as the dependent variable and as the weight of seven carcass parts. Coefficients of determination and multiple correlation were calculated. Data for each grade were analyzed using the following multiple linear regression model:

$$
\mathrm{y}_{\mathrm{i}=} \mu+\beta_{1} \mathrm{x}_{\mathrm{i} 1}+\beta_{2} \mathrm{x}_{\mathrm{i} 2}+\beta_{3} \mathrm{x}_{\mathrm{i3}}+\beta_{4} \mathrm{x}_{\mathrm{i} 4}+\beta_{5} \mathrm{x}_{\mathrm{i} 5}+\beta_{6} \mathrm{x}_{\mathrm{i} 6}+\beta_{7} \mathrm{x}_{\mathrm{i} 7}
$$

where $\mu$ was the intercept, $\beta$ was the slope for the independent variable $x_{i j}$ which was the weight of carcass part estimated by AutoFomm III, $\mathrm{X}_{\mathrm{i} 1}$ was the belly, $\mathrm{x}_{\mathrm{i} 2}$ was the neck bone-out, $\mathrm{x}_{\mathrm{i} 3}$ was the spare rib, $\mathrm{x}_{\mathrm{i} 4}$ was the loin bone-out, $\mathrm{x}_{\mathrm{i} 5}$ was the tenderloin, $\mathrm{x}_{\mathrm{i} 6}$ was the shoulder, and $\mathrm{x}_{\mathrm{i} 7}$ was the ham bone-out. All statistical analyses were performed using SPSS software (version 21.0, SPSS, Chicago, IL, USA).

\section{RESULTS AND DISCUSSION}

The Korean grade evaluation of pork is only based on carcass quality and meat quality for the whole pig carcass after slaughtering. The carcass quality is determined by carcass weight and 
backfat thickness (Table 1). The meat quality is determined by subjective marbling level, meat color, fat color, degrees of maturity, and texture. Therefore, the weight of pork primal cut is not known with the Korean pork grade system until the primal cut is separated. Pork price is set on different standards between producers and consumers. It is determined by the carcass grade into the producer and by various primal and commercial cut into the consumer $[3,12]$. In addition to the pig carcass grade system, it is necessary to estimate the amount of primal cut for determining the pork price. Non-invasive methods have been used to determine the cutting yield of pig carcasses in European countries and North America since the early 2000s [6,13-16]. AutoFom I shows a smaller residual root mean squares error than the European Union standard when measuring the lean meat percentage (ham, loin, and shoulder) of pig carcasses [17]. In addition, AutoFom I shows a high prediction accuracy in residual root mean squares error and regression coefficient for weights of untrimmed primal cuts of pigs [18-20]. AutoFom III is an image analysis software version after modifying and improving AutoFom I. Our previous study has verified that the prediction with AutoFom III for Korean slaughter pigs has a high accuracy [11]. The present study estimated the amount of pork primal cut using AutoFom III and investigated the correlation between the amount of pork primal cut and each carcass grade.

A total of 419,321 pig carcasses were graded: grade $1^{+}$for 145,872 heads (34.8\%), grade 1 for 157,833 heads (37.6\%), and grade 2 for 115,616 heads (27.6\%). Table 2 shows carcass weight and backfat thickness of each carcass grade. As a result of $F$-test and White's-test to investigate the distribution of the carcass weight and the backfat thickness for each grade, the distribution of both data showed heteroscedasticity. There were significant differences in carcass weight and backfat thickness among the three grades by t-test of heteroscedasticity variance $(p<0.0001)$. The lower the grade, the larger the standard deviation value of carcass weight and backfat thickness (Table 2). In other words, the standard deviation of carcass weight or backfat thickness was smaller for a highquality meat.

To find out the amount of pork primal cut, weights of seven primal cuts (belly, neck, loin, tenderloin, spare ribs, shoulder, and ham) were estimated using AutoFom III. All weights of seven primal cuts showed significant differences among the three grades (Table 3). The higher the grade is, the smaller the standard deviation is. The weight was higher in the order of ham, belly, and shoulder for all three grades (Table 3). The ratio of belly weight, which is the most expensive cut in Korea, to carcass weight was investigated among the grades. There were significant differences in the ratio of belly weight to carcass weight among the grades $(p<0.001)$, with grade 2 being the highest and grade $1^{+}$being the lowest (grade $2: 14.1 \pm 0.62 \%$, grade $1: 14.0 . \pm 0.49 \%$, grade $1^{+}: 13.9$ $\pm 0.45 \%$ as mean \pm standard deviation). This result shows that the higher the grade is, the smeller the ratio of belly is. Therefore, it is considered that the current Korean pig carcass grade system needs supplementary means.

Excess kurtosis and skewness were calculated to investigate distribution characteristics. Weights of seven primal cuts were estimated with AutoFom III. Excess kurtosis of belly, neck, spare ribs,

Table 2. Pig carcass weight and backfat thickness according to the Grading System for Pig Products in Korea

\begin{tabular}{lcccc}
\hline & Grade 1 $^{+}$ & Grade 1 & Grade 2 $^{\mathrm{a}}$ & $\boldsymbol{p}$-value \\
\hline Carcass weight $(\mathrm{kg})$ & $87.6 \pm 2.64^{\mathrm{c}}$ & $87.9 \pm 5.27^{\mathrm{a}}$ & $87.7 \pm 8.98^{\mathrm{b}}$ & 0.000 \\
Backfat thickness $(\mathrm{mm})$ & $21.2 \pm 2.06^{\mathrm{c}}$ & $27.8 \pm 3.90^{\mathrm{a}}$ & $23.2 \pm 7.33^{\mathrm{b}}$ & 0.000 \\
\hline
\end{tabular}

Each value is presented as mean $\pm \mathrm{SD}$.

Population numbers for Grades $1^{+}, 1$, and 2 are 145,872, 157,833, and 115,616, respectively.

${ }^{1)} p$-value is obtained by $t$-test of heteroscedasticity variance.

${ }^{a-c}$ Different superscripts in the same row differ significantly in the analysis of heteroscedasticity variance. 
Table 3. Weights of seven carcass primal cuts estimated with AutoFom III (unit: kg)

\begin{tabular}{lcccc}
\hline & Grade $1^{+}$ & Grade 1 & Grade 2 & $\boldsymbol{p}^{- \text {-value }}$ \\
\hline Belly & $12.14 \pm 0.544^{\mathrm{c}}$ & $12.27 \pm 0.894^{\mathrm{b}}$ & $12.55 \pm 1.528^{\mathrm{a}}$ & 0.000 \\
Neck bone-out & $4.58 \pm 0.199^{\mathrm{a}}$ & $4.47 \pm 0.318^{\mathrm{b}}$ & $4.40 \pm 0.462^{\mathrm{c}}$ & 0.000 \\
Loin bone-out & $5.68 \pm 0.495^{\mathrm{a}}$ & $5.63 \pm 0.633^{\mathrm{b}}$ & $5.48 \pm 0.800^{\mathrm{c}}$ & 0.000 \\
Tenderloin & $0.97 \pm 0.055^{\mathrm{a}}$ & $0.96 \pm 0.078^{\mathrm{b}}$ & $0.95 \pm 0.106^{\mathrm{c}}$ & 0.000 \\
Spare ribs & $3.64 \pm 0.114^{\mathrm{b}}$ & $3.65 \pm 0.205^{\mathrm{a}}$ & $3.62 \pm 0.322^{\mathrm{c}}$ & 0.000 \\
Shoulder & $8.13 \pm 0.281^{\mathrm{a}}$ & $8.12 \pm 0.479^{\mathrm{b}}$ & $8.04 \pm 0.717^{\mathrm{c}}$ & 0.002 \\
Ham bone-out & $17.04 \pm 0.790^{\mathrm{a}}$ & $16.98 \pm 1.189^{\mathrm{b}}$ & $16.71 \pm 1.667^{\mathrm{c}}$ & 0.000 \\
\hline
\end{tabular}

Each value is presented as mean $\pm \mathrm{SD}$.

Population numbers for Grades $1^{+}, 1$, and 2 are 145,872, 157,833, and 115,616, respectively.

${ }^{1)} p$-value is obtained by $t$-test of heteroscedasticity variance.

${ }^{a-c}$ Different superscripts in the same row differ significantly in the analysis of heteroscedasticity variance.

and shoulder showed a platykuric distribution with negative values $(\mathrm{k}<0$, Table 4$)$. Excess kurtosis of loin, tenderloin and ham showed negative or positive values depending on the grade. Loin with grade 2 and tenderloin and ham with Grades 1 and 2 had negative excess kurtosis $(\mathrm{k}<0)$, indicating a platykuric distribution. Besides loin, tenderloin, and ham with grade $1^{+}$, loin of grade 2 also had positive values $(k>0)$, indicating a leptokurtic distribution (Table 4). Belly and spare ribs had negative skewness that skewed to the left, whereas loin had positive skewness that skewed to the right (Table 4). Neck, tenderloin, shoulder, and ham showed negative or positive skewness depending on the grade. All seven primal cuts had skewness. However, loin, tenderloin, spare ribs, and shoulder were approximate in mean, median, and mode. Thus, they were close to symmetry (Tables 3 and 4).

To investigate the relationship between pig carcass grade and pork primal cut, regression analysis was carried out. Multiple regression analysis was performed with carcass weight as a dependent variable and each primal cut as independent variables. Intercept and independent variables are shown in Table 5. Substituting the intercept and the slope in Table 5, the regression equation for each grade is shown below:

$$
\begin{aligned}
& \text { Grade } 1^{+}: \mathrm{y}=0.28+2.59 \mathrm{x}_{1}+14.40 \mathrm{x}_{2}-24.33 \mathrm{x}_{3}-7.10 \mathrm{x}_{4}-46.56 \mathrm{x}_{5}+10.56 \mathrm{x}_{6}+4.66 \mathrm{x}_{7} \\
& \text { Grade 1: } \mathrm{y}=-3.56+3.00 \mathrm{x}_{1}+17.25 \mathrm{x}_{2}-29.12 \mathrm{x}_{3}-8.07 \mathrm{x}_{4}-56.56 \mathrm{x}_{5}+11.15 \mathrm{x}_{6}+5.48 \mathrm{x}_{7} \\
& \text { Grade 2: } \mathrm{y}=-4.96+3.32 \mathrm{x}_{1}+17.14 \mathrm{x}_{2}-32.19 \mathrm{x}_{3}-8.27 \mathrm{x}_{4}-64.88 \mathrm{x}_{5}+12.19 \mathrm{x}_{6}+6.06 \mathrm{x}_{7}
\end{aligned}
$$

Coefficients of determination and multiple correlation for each grade were higher for the lower grade (Table 6). The prediction accuracy with AutoFom III was higher in the present study than that in our previous study [11]. This difference of accuracy could be due to the following two reasons: i) difference in the number of pork primal cuts (11 primal cuts in the previous study and 7 primal cuts in the present study) estimated with AutoFom III. AutoFom III was less accurate for pork primal cuts with less amounts [11]; ii) difference in the number of samples (419,321 heads in this study and 162 heads in the previous study). A high prediction accuracy of AutoFom III was shown for pork belly muscle thickness and ham lean meat percentage $\left(r^{2}=0.98\right.$ and $r^{2}=0.93$, respectively) [10]. In Spain, when AutoFom III was used to predict subcutaneous fat thickness of ham, the final quality of dry-cured ham was improved [21].

The consumption and price of pork primal cuts are higher in the order of belly, neck, and shoulder in Korea [22,23]. The price of pork belly, which is the most preferred primal cut of Koreans, is more than four times per $\mathrm{kg}$ of primal cut than the price of ham, which is the unfavorable primal 
Pig carcass grade and pork primal cuts

Table 4. Distribution characteristics of seven carcass primal cuts analyzed by AutoFom III (unit: kg)

\begin{tabular}{|c|c|c|c|c|c|c|}
\hline & Median & Mode & Min & Max & Excess kurtosis & Skewness \\
\hline \multicolumn{7}{|l|}{ Belly } \\
\hline Grade $1^{+}$ & 12.12 & 12.16 & 10.66 & 13.64 & -0.224 & 0.099 \\
\hline Grade 1 & 12.24 & 11.66 & 9.66 & 15.26 & -0.871 & 0.106 \\
\hline Grade 2 & 12.81 & 10.90 & 8.50 & 16.74 & -0.951 & 0.105 \\
\hline \multicolumn{7}{|c|}{ Neck bone-out } \\
\hline Grade $1^{+}$ & 4.48 & 4.46 & 3.14 & 5.14 & -0.113 & -0.141 \\
\hline Grade 1 & 4.44 & 4.24 & 2.32 & 5.36 & -0.712 & 0.095 \\
\hline Grade 2 & 4.34 & 4.16 & 2.78 & 5.96 & -0.444 & 0.357 \\
\hline \multicolumn{7}{|l|}{ Loin bone-out } \\
\hline Grade $1^{+}$ & 5.70 & 5.70 & 1.58 & 7.98 & 0.336 & -0.243 \\
\hline Grade 1 & 5.64 & 5.72 & 0.24 & 7.94 & -0.003 & -0.126 \\
\hline Grade 2 & 5.46 & 5.48 & 1.16 & 8.42 & 0.065 & -0.004 \\
\hline \multicolumn{7}{|l|}{ Tenderloin } \\
\hline Grade $1^{+}$ & 0.98 & 0.98 & 0.50 & 1.18 & 0.528 & -0.282 \\
\hline Grade 1 & 0.96 & 0.94 & 0.36 & 1.22 & -0.180 & -0.043 \\
\hline Grade 2 & 0.94 & 0.90 & 0.28 & 1.32 & -0.108 & 0.198 \\
\hline \multicolumn{7}{|l|}{ Spare ribs } \\
\hline Grade $1^{+}$ & 3.64 & 3.64 & 3.12 & 4.26 & -0.570 & 0.004 \\
\hline Grade 1 & 3.62 & 3.44 & 2.94 & 4.48 & -1.074 & 0.168 \\
\hline Grade 2 & 3.58 & 3.32 & 2.56 & 4.76 & -0.654 & 0.369 \\
\hline \multicolumn{7}{|l|}{ Shoulder } \\
\hline Grade $1^{+}$ & 8.12 & 8.12 & 6.54 & 9.18 & -0.361 & -0.073 \\
\hline Grade 1 & 8.08 & 7.70 & 5.56 & 9.66 & -0.910 & 0.135 \\
\hline Grade 2 & 7.94 & 7.48 & 5.76 & 10.36 & -0.554 & 0.381 \\
\hline \multicolumn{7}{|c|}{ Ham bone-out } \\
\hline Grade $1^{+}$ & 17.06 & 17.00 & 11.32 & 19.82 & 0.097 & -0.204 \\
\hline Grade 1 & 16.92 & 16.48 & 7.80 & 20.58 & -0.499 & 0.038 \\
\hline Grade 2 & 16.50 & 16.02 & 9.72 & 22.44 & -0.319 & 0.304 \\
\hline
\end{tabular}

Population numbers for Grades $1^{+}, 1$, and 2 are 145,872, 157,833, and 115,616, respectively.

Table 5. Intercepts and slopes of seven carcass parts in regression function

\begin{tabular}{lccc}
\hline & Grade $\mathbf{1}^{+}$ & Grade 1 & Grade 2 \\
\hline Intercept & 0.28 & -3.56 & -4.96 \\
Linear regression slope & & & \\
Belly $\left(\mathrm{X}_{1}\right)$ & 2.59 & 3.00 & 3.32 \\
Neck bone-out $\left(\mathrm{X}_{2}\right)$ & 14.40 & 17.25 & 17.14 \\
Spare ribs $\left(\mathrm{X}_{3}\right)$ & -24.33 & -29.12 & -32.19 \\
Loin bone-out $\left(\mathrm{X}_{4}\right)$ & -7.10 & -8.07 & -8.27 \\
Tenderloin $\left(\mathrm{X}_{5}\right)$ & -46.56 & -56.56 & -64.88 \\
Shoulder $\left(\mathrm{X}_{6}\right)$ & 10.56 & 11.15 & 12.19 \\
Ham bone-out $\left(\mathrm{X}_{7}\right)$ & 4.66 & 5.48 & 6.06 \\
\hline
\end{tabular}

Population numbers for Grades $1^{+}, 1$, and 2 are 145,872, 157,833, and 115,616, respectively. 
Table 6. Coefficients of determination and multiple correlation of animal products according to the grading system

\begin{tabular}{lccc}
\hline & Grade 1 $^{+}$ & Grade 1 & Grade 2 \\
\hline Coefficient of determination & 0.941 & 0.982 & 0.993 \\
Adjusted coefficient of determination & 0.941 & 0.982 & 0.991 \\
Coefficient of multiple correlation & 0.991 & 0.993 & 0.996 \\
\hline
\end{tabular}

Population numbers for Grades $1^{+}, 1$, and 2 are 145,872, 157,833, and 115,616, respectively.

cut. Therefore, it is necessary to consider the price of pigs by measuring the amount of pork primal cut. In this study, distribution characteristics of data for each Korean grade of pork carcasses and their seven primal cuts estimated with AutoFom III were investigated in order to be clear about correlation between pork carcass grade and pork primal cuts. Regression equations with high reliability were derived for the relationship between each grade and each of seven primal cuts (belly, neck, loin, tenderloin, spare ribs, shoulder, and ham). In conclusion, these regression equations based on the AutoForm III software will be a useful tool for the analysis of specific grades of pig carcasses. The high reliability prediction of primal cuts is advantageous for the management of slaughterhouses to optimize their product sorting prior to carcasses entering the cold room. Results of this study can be used as a base to suggest the optimal price of pigs in the market and the direction of pig breeding in the pig farming industry.

\section{REFERENCES}

1. Korea Institute for Animal Product Quality Evaluation. 2016 Animal products grading statistical yearbook. Sejong: Korea Institute for Animal Product Quality Evaluation; 2016. Report No.: 11-B552679-000006-10.

2. Korean Ministry of Agriculture. Food and Rural Affairs Notification 2014-4. 2014 [cited 2021 Sep 10]. Available from: http://www.law.go.kr/LSW//admRulInfoP. do?admRulSeq=2100000196314\&chrClsCd=10201

3. Oh SH, See MT. Pork preference for consumers in China, Japan and South Korea. AsianAustralas J Anim Sci. 2012;25:143-50. https://doi.org/10.5713/ajas.2011.11368

4. Mitchell AD, Scholz AM, Pursel VG, Evock-Clover CM. Composition analysis of pork carcasses by dual-energy x-ray absorptiometry. J Anim Sci. 1998;76:2104-14. https://doi. org $/ 10.2527 / 1998.7682104 \mathrm{x}$

5. Collewet G, Bogner P, Allen P, Busk H, Dobrowolski A, Olsen E, et al. Determination of the lean meat percentage of pig carcasses using magnetic resonance imaging. Meat Sci. 2005;70:563-72. https://doi.org/10.1016/j.meatsci.2005.02.005

6. Font i Furnols M, Gispert M. Comparison of different devices for predicting the lean meat percentage of pig carcasses. Meat Sci. 2009;83:443-6. https://doi.org/10.1016/j.meatsci.2009.06.018

7. Aalhus JL, López-Campos Ó, Prieto N, Rodas-González A, Dugan MER, Uttaro B, et al. Review: Canadian beef grading - opportunities to identify carcass and meat quality traits valued by consumers. Can J Anim Sci. 2014;94:545-56. https://doi.org/10.4141/cjas-2014-038

8. Kress K, Hartung J, Jasny J, Stefanski V, Weiler U. Carcass characteristics and primal pork cuts of gilts, boars, immunocastrates and barrows using AutoFOM III data of a commercial abattoir. Animals. 2020;10:1912. https://doi.org/10.3390/ani10101912

9. Scholz AM, Bünger L, Kongsro J, Baulain U, Mitchell AD. Non-invasive methods for the determination of body and carcass composition in livestock: dual-energy X-ray absorptiometry, computed tomography, magnetic resonance imaging and ultrasound: invited review. Animal. 
2015;9:1250-64.https://doi.org/10.1017/S1751731115000336

10. Janiszewski P, Borzuta K, Lisiak D, Grześkowiak E, Stanisławski D. Prediction of primal cuts by using an automatic ultrasonic device as a new method for estimating a pig-carcass slaughter and commercial value. Anim Prod Sci. 2019;59:1183-9. https://doi.org/10.1071/AN15625

11. Choi JS, Kwon KM, Lee YK, Joeng JU, Lee KO, Jin SK, et al. Application of AutoFom III equipment for prediction of primal and commercial cut weight of Korean pig carcasses. AsianAustralas J Anim Sci. 2018;31:1670-6. https://doi.org/10.5713/ajas.18.0240

12. Nam KH, Choe YC. The estimation of the demand function of pork cuts. J Agric Ext Community Dev. 2016;23:27-37. https://doi.org/10.12653/jecd.2016.23.1.0027

13. Furnols M, Teran MF, Gispert M. Estimation of lean meat content in pig carcasses using X-ray Computed Tomography and PLS regression. Chemometr Intell Lab Syst. 2009;98:31-7. https://doi.org/10.1016/j.chemolab.2009.04.009

14. Fortin A, Tong AKW, Robertson WM, Zawadski SM, Landry SJ, Robinson DJ, et al. A novel approach to grading pork carcasses: computer vision and ultrasound. Meat Sci. 2003;63:45162. https://doi.org/10.1016/S0309-1740(02)00104-3

15. Pathak V, Singh VP, Sanjay Y. Ultrasound as a modern tool for carcass evaluation and meat processing: a review. Int J Meat Sci. 2011;1:83-92. https://doi.org/10.3923/ijmeat.2011.83.92

16. Uttaro B, Zawadski S. Prediction of pork belly fatness from the intact primal cut. Food Control. 2010;21:1394-401. https://doi.org/10.1016/j.foodcont.2010.03.012

17. Busk H, Olsen EV, Brøndum J. Determination of lean meat in pig carcasses with the Autofom classification system. Meat Sci. 1999;52:307-14. https://doi.org/10.1016/S03091740(99)00007-8

18. Fortin A, Tong AKW, Robertson WM. Evaluation of three ultrasound instruments, CVT-2, UltraFom 300 and AutoFom for predicting salable meat yield and weight of lean in the primals of pork carcasses. Meat Sci. 2004;68:537-49. https://doi.org/10.1016/j.meatsci.2004.05.006

19. Gispert M, Font i Furnols M, Diestre A, Batalle J. The AUTOFOM: new equipment of carcasses clasification approved for Spain. Eurocarne (España). 2002:110:69-74.

20. Lisiak D, Duziński K, Janiszewski P, Borzuta K, Knecht D. A new simple method for estimating the pork carcass mass of primal cuts and lean meat content of the carcass. Anim Prod Sci. 2015;55:1044-50. https://doi.org/10.1071/AN13534

21. Masferrer G, Carreras R, Font-i-Furnols M, Gispert M, Marti-Puig P, Serra M. On-line Ham Grading using pattern recognition models based on available data in commercial pig slaughterhouses. Meat Sci. 2018;143:39-45. https://doi.org/10.1016/j.meatsci.2018.04.011

22. Park HN. Only pork belly and neck are doing well ... find a way to use the non-preferred part! [Internet]. Nongmin Newspaper. 2020 [cited 2021 Sep 11]. Available from: https://www. nongmin.com/news/NEWS/ECO/COW/320433/view

23. Ok MY. After the aftermath of COVID-19, the back leg meat ... the proportion of pork belly "Rising". [Internet]. Farminsight. 2020 [cited 2021 Sep 11]. Available from: http://www. farminsight.net/news/articleView.html?idxno=6660 